\title{
High-Throughput MonoSpin Extraction for Quantification of Cardiovascular Drugs in Serum Coupled to High-Performance Liquid Chromatography-Mass Spectrometry
}

\author{
Akira Namera $^{1 *}$, Takeshi Saito ${ }^{2}$, Yoshimoto Seki ${ }^{3}$, Taro Mizutani ${ }^{4}$, Kazuhiro Murata ${ }^{1}$ and Masataka Nagao ${ }^{1}$ \\ ${ }^{\prime}$ Department of Forensic Medicine, Graduate School of Biomedical and Health Sciences, Hiroshima University, \\ Hiroshima 734-8553, Japan \\ 2Department of Emergency and Critical Care Medicine, Tokai University School of Medicine, Kanagawa 259-1143, Japan \\ ${ }^{3}$ Ibaraki Prefectural Central Hospital, Ibaraki 309-1703, Japan \\ ${ }^{4}$ Chikusei City Medical Director, Ibaraki 308-8616, Japan
}

Received: 24 May 2018; accepted: 15 June 2018

\begin{abstract}
A novel method coupling spin column extraction with high-performance liquid chromatography-mass spectrometry was developed for simultaneous extraction of $\beta$-blockers and calcium channel blockers from human serum. Sample loading, washing, and elution were accomplished via centrifugation of the column, in which mixed-mode monolithic silica bonded to a $\mathrm{C}_{18}$ reversed phase, and a cation-exchange phase was packed in a spin column. The serum sample $(0.2 \mathrm{~mL}) \mathrm{pH}$ was adjusted to 3 and the analytes adsorbed onto the column were eluted with $0.1 \mathrm{~mL} \mathrm{MeOH}$ containing $2 \% \mathrm{NH}_{3}$. The recoveries of the tested drugs were $76-108 \%$. A linear curve was observed up to a concentration of $500 \mathrm{ng} / \mathrm{mL}$ of the target drugs in serum $\left(r^{2}>0.996\right)$. The intra-day relative standard deviations at three different concentrations were $0.6-9.6 \%$. The limits of detection were $2 \mathrm{ng} / \mathrm{mL}$. The proposed method was successfully applied to clinical and forensic cases.

Keywords: $\beta$-blockers, calcium channel blockers, monolithic silica, solid-phase extraction, mix-mode
\end{abstract}

\section{Introduction}

The number of cardiovascular patients worldwide continues to rise every year, and the total number of deaths due to cardiovascular disease reached 17.3 million per year according to the WHO causes-of-death 2008 summary tables [1]. With the increase in the number of patients, the production of cardiovascular medications is increasing correspondingly worldwide. In particular, antihypertensive agents, such as $\beta$-blockers (BBs) and calcium channel blockers (CCBs), occupy a large share of the pharmaceutical market due to the increase in the elderly population, many of whom have hypertension. BBs are competitive antagonists at $\beta$-adrenergic receptor sites and are used to treat cardiovascular disorders, such as hypertension, angina pectoris, myocardial infarction, and cardiac arrhythmias. CCBs are used in the management of angina pectoris and hypertension. They act via the inhibition of the cellular influx of calcium, which is responsible for maintaining the plateau phase of the action potential. Combination therapy with BBs and CCBs is often necessary, and such dosage forms have been formulated [2-4]. Although BBs and CCBs have different mechanisms of action in humans, their physiological and toxic effects are similar. As a result of the growing use and availability of cardiovascular medications, there has been a rise in the number of toxic exposures. $\mathrm{BB}$ and $\mathrm{CCB}$ overdoses, which are often the result of intentional or accidental ingestion, patient error, or drug interactions, are associated with significant morbidity and mortality [5-7]. Although BB and CCB serum levels are not generally monitored in clinical laboratories, the therapeutic blood concentration is relatively narrow, as shown in Table 1 [8-11]. Therefore, a simple and accurate quantification method would be highly useful in clinical and forensic laboratories to quickly monitor the concentration of those medicines.

*Author for correspondence: namera@hiroshima-u.ac.jp
Table 1. Therapeutic concentrations and physicochemical properties of targets

\begin{tabular}{lccc}
\hline & Therapeutic concentration $(\mathrm{ng} / \mathrm{mL})$ & $\mathrm{p} K_{\mathrm{a}}$ & $\log P$ \\
\hline B-blocker & & & \\
Pindolol & $20-150$ & 9.54 & 1.83 \\
Carazolol & $<15$ & 9.52 & 3.73 \\
Bisoprolol & $10-100$ & 9.57 & 2.15 \\
Propranolol & $20-900$ & 9.53 & 3.48 \\
Carvedilol & $20-150$ & 7.97 & 4.11 \\
Ca-blocker & & & \\
Nicardipine & $70-100$ & 8.18 & 4.65 \\
Amlodipine & $5-15$ & 9.46 & 3.17 \\
Nifedipine & $25-100$ & 5.33 & 2.2 \\
Nitrendipine & $10-50$ & 5.43 & 2.88 \\
Felodipine & $1-12$ & 5.39 & 3.86 \\
\hline
\end{tabular}

Many methods have been reported for the individual assays of BBs [12-14] and CCBs [15-17] in human samples. However, few methods have been reported for the simultaneous assay of both drugs $[18,19]$. Moreover, the previous sample preparation procedures are tedious and time-consuming. In this study, MonoSpin extraction is adopted into a simple procedure to reduce the sample preparation time and to perform the extraction from a limited volume sample.

\section{Experimental}

Materials and Methods. Bisoprolol was purchased from The United States Pharmacopeial Convention, Inc. (Rockville, MD, USA). Carazolol, pindolol, propranolol, nicardipine, nifedipine, and nitrendipine were from Wako Pure Chemicals Industries Ltd. (Osaka, JAPAN). Carvedilol and amlodipine were from LKT Laboratories Inc. (St. Paul, MN, USA). Felodipine was obtained from Sigma-Aldrich (St. Louis, MO, USA). Propranolol-d $\mathrm{d}_{7}$, which was used as an internal standard (IS), was purchased from Toronto Research Chemicals (Toronto, Canada).

This is an open-access article distributed under the terms of the Creative Commons Attribution-NonCommercial 4.0 International License (https://creativecommons.org/licenses/by-nc/4.0/), which permits unrestricted use, distribution, and reproduction in any medium for non-commercial purposes, provided the original author and source are credited, a link to the CC License is provided, and changes - if any - are indicated. 
All the tested drugs were dissolved in acetonitrile or 50\% aqueous acetonitrile to obtain stock standard solutions $(1.0 \mathrm{mg} / \mathrm{mL})$, which were stored at $4{ }^{\circ} \mathrm{C}$ in a refrigerator. The other purchased solvents were of the highest quality and were manufactured by Wako Pure Chemical Industries Ltd. Human serum was purchased from MP Biomedicals Inc., and serum samples obtained from the patient were maintained at $-20^{\circ} \mathrm{C}$ until required for analysis. MonoSpin $\mathrm{C}_{18}$ and $\mathrm{C}_{18} \mathrm{CX}$ were purchased from GL Science (Tokyo, Japan).

Extraction Procedure by MonoSpin $\mathbf{C}_{\mathbf{1 8}}$. Human serum $(200 \mu \mathrm{L})$, Sørensen's buffer $(0.1 \mathrm{M}, \mathrm{pH} 10,800 \mu \mathrm{L})$, and propranolol- $\mathrm{d}_{7}$ (IS; $50 \mu \mathrm{g} / \mathrm{mL}, 4 \mu \mathrm{L}$ ) were added to a $2.0 \mathrm{~mL}$ siliconized microtube. The tube was vortex-mixed for $30 \mathrm{~s}$ and then centrifuged at $13,400 \mathrm{rpm}(12,100 \times g)$ for $5 \mathrm{~min}$ by using a MiniSpin ${ }^{\circledR}$ (Eppendorf AG, Hamburg, Germany). The supernatant was exposed to MonoSpin extraction, as described in our previous paper [20]. Briefly, the MonoSpin $\mathrm{C}_{18}$ column was installed in a siliconized microtube $(2 \mathrm{~mL})$, and pre-activated with $\mathrm{MeOH}$ and the buffer by centrifugation at $3000 \mathrm{rpm}$ $(600 \times g)$ for $30 \mathrm{~s}$ before extraction. The diluted serum sample $(1.0 \mathrm{~mL})$ was directly loaded into the pre-activated column, and the column was centrifuged at $3000 \mathrm{rpm}$ for $2 \mathrm{~min}$. The column was then washed with $0.3 \mathrm{~mL}$ buffer by centrifugation at $3000 \mathrm{rpm}$ for $1 \mathrm{~min}$. Finally, the column was installed in a new siliconized microtube $(1.5 \mathrm{~mL})$, and the analytes adsorbed onto the column were eluted with $0.1 \mathrm{~mL}$ of $\mathrm{MeOH}$ at $3000 \mathrm{rpm}$ for $2 \mathrm{~min}$. An aliquot $(5 \mu \mathrm{L})$ was then injected into the high-performance liquid chromatography-mass spectrometry (HPLC-MS) system without evaporation.

Extraction Procedure by MonoSpin $\mathrm{C}_{18}-\mathrm{CX}$. The general schematic procedure of sample preparation is similar to the $\mathrm{C}_{18}$ extraction described above. When pre-activating a $\mathrm{C}_{18}-\mathrm{CX}$ spin column, loading a sample into the column, and washing the column, the column was installed in a siliconized microtube $(2 \mathrm{~mL})$. Prior to extraction, the column was pre-activated with $0.5 \mathrm{~mL} \mathrm{MeOH}$ and $0.5 \mathrm{~mL}$ citrate buffer $(10 \mathrm{mM}, \mathrm{pH} 3)$ by centrifugation at $5000 \mathrm{rpm}(1700 \times \mathrm{g})$ for $1 \mathrm{~min}$. The serum sample $(0.2 \mathrm{~mL})$, citrate buffer $(0.8 \mathrm{~mL})$, and IS solution ( $4 \mu \mathrm{L}, 50 \mu \mathrm{g} / \mathrm{mL}$, propranolol- $\mathrm{d}_{7}$ ) were directly loaded onto the pre-activated column, and the column was centrifuged at $5000 \mathrm{rpm}$ for $1 \mathrm{~min}$. In this acidic solution, the acidic drugs were in the non-ionic form and were adsorbed onto the reversed phase in the column, and the basic drugs were in the ionic form and were adsorbed onto the cation-exchange phase. The column was then washed with $0.4 \mathrm{~mL}$ of citrate buffer by centrifugation at $5000 \mathrm{rpm}$ for $1 \mathrm{~min}$. Finally, the column was installed in a new microtube $(1.5 \mathrm{~mL})$, and the analytes adsorbed onto the column were eluted with $0.1 \mathrm{~mL}$ of $\mathrm{MeOH}$ containing $2 \% \mathrm{NH}_{3}$ via centrifugation at $5000 \mathrm{rpm}$ for $1 \mathrm{~min}$. A $5 \mu \mathrm{L}$ volume of the eluate was then injected into the HPLC-MS system without evaporation.

LC-MS System. HPLC-MS was performed using an LC1100/MSD system (Agilent Technologies, Palo Alto, CA, USA). A reversed-phase InertSustain ${ }^{\circledR} \mathrm{C}_{8}(150 \mathrm{~mm} \times 2.1 \mathrm{~mm}$ internal diameter; pore size of $3 \mu \mathrm{m}$; GL Sciences, Tokyo, Japan) equipped with a pre-column of the same phase was used for the analyses. The flow rate of the mobile phase was set at $0.2 \mathrm{~mL} / \mathrm{min}$, and the oven temperature was maintained at $40{ }^{\circ} \mathrm{C}$. The mobile phase was composed of ammonium formate (10 mM, containing $0.1 \%$ formic acid, $\mathrm{pH} 3.3$ ) as solvent A and acetonitrile or methanol as solvent $\mathrm{B}$. The injection volume was $5 \mu \mathrm{L}$ for each sample. The electrospray ionization mass spectrometer was operated in positive ion and selective ion monitoring modes. The drying gas (nitrogen) temperature was set at $350{ }^{\circ} \mathrm{C}$, the drying gas flow at $13 \mathrm{~L} / \mathrm{min}$, nebulizer pressure at $50 \mathrm{psi}$, and capillary voltage at $2500 \mathrm{~V}$. The fragmentor voltage was set at $150 \mathrm{~V}$. The protonated ion $[\mathrm{M}+\mathrm{H}]^{+}$of each target used for quantification was as follows: $\mathrm{m} / \mathrm{z} 249$ (pindolol), 260 (propranolol), 294 (amlodipine), 299 (carazolol), 315 (nifedipine and nitrendipine), 326 (bisoprolol), 338 (felodipine), 407 (carvedilol), 480 (nicardipine), and 267 (propranolol- $\mathrm{d}_{7}$ ). HPLC-MS data acquisition and integration were performed using the Agilent Technologies LC-MSD ChemStation ${ }^{\circledR}$ chromatographic analysis software. The concentration of each drug was calculated from calibration curves using an internal standard.

Method Validation. The matrix effect (ME) and recovery (RE) of the extraction procedure were determined by comparing the absolute peak areas of analytes obtained in sets 1-3 as follows:

$$
\begin{aligned}
& \operatorname{ME}(\%)=(B / A) * 100 \\
& \operatorname{RE}(\%)=(C / B) * 100
\end{aligned}
$$

where $A$ is the total peak area obtained in pure standard solutions (set 1), $B$ is the corresponding peak area for standards spiked into the serum extracts after extraction (set 2), and $C$ is the corresponding peak area for standards spiked before extraction (set 3).

The peak area ratios between each analyte and the internal standard were plotted against analyte concentrations to obtain a calibration curve, which was analyzed by unweighted linear regression analysis to obtain the best fit to a straight line. Patients' samples with analyte concentrations greater than the highest calibration standard were diluted two- to fourfold with drug-free serum in order to achieve a suitable concentration that was within the calibration range.

To determine the intra-day accuracy and precision of the assay, serum samples were prepared separately by spiking the analyte at the final concentrations of $A, B$, and $C$ and then analyzed using five replicates within a run using the procedure described above.

\section{Results and Discussion}

Optimization of Sample Extraction. MonoSpin $\mathrm{C}_{18}$ and $\mathrm{C}_{18}$-CX were utilized to extract the tested drugs from the serum, yielding a high recovery. As shown in Figure 1 , when the $C_{18}$ column was used for the extraction, the recoveries of the tested drugs were $45 \%$ to $80 \%$. The loss of pindolol was due to a lack of retention to the sorbent in sample load or washing. In a reversed phase column, such as $\mathrm{C}_{18}$, silica gel coated with an

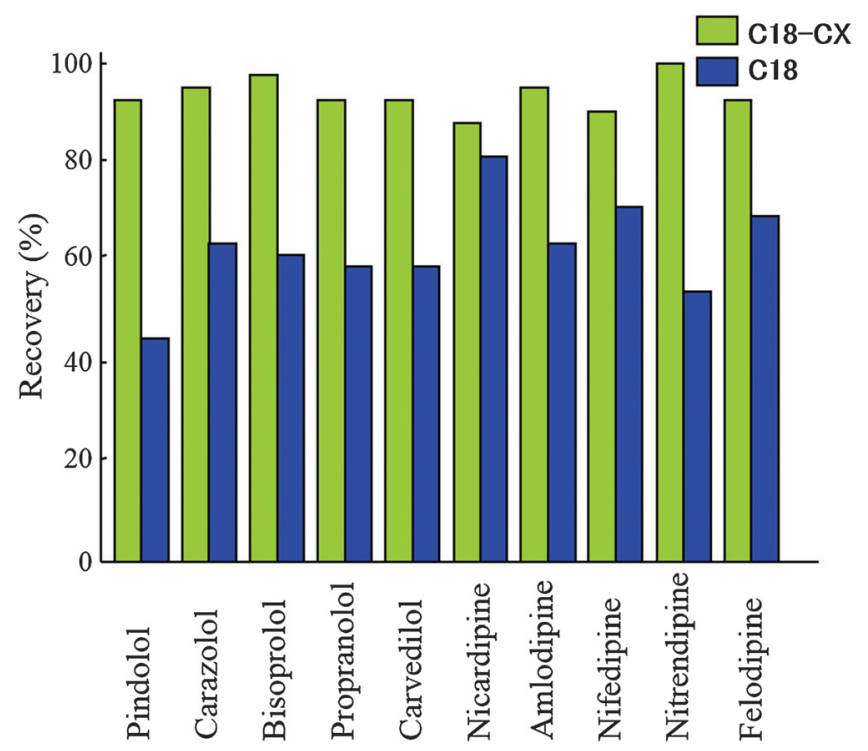

Figure 1. Effect of the recovery on the sorbent 
octadecyl surface functionality is used as the sorbent, and a polar solvent such as methanol is used for elution. There seems to be a relationship between the recovery rate and the oil-water partition coefficient $\left(P_{\mathrm{ow}}\right)$ of the analyte, although this phenomenon depends on the sorbent used. In previous experimental studies, analytes with a $\log P$ of 2 to 3 could be extracted completely using $\mathrm{C}_{18}$ surfaces [21]. Although this study was not completely based on this theory, high recovery tended to occur for drugs with a high $\log P$, as shown in Table 1 . Nicardipine $(\log P=$ 4.65) was extracted (more than $80 \%$ ); however, pindolol $(\log \mathrm{P}=$ 1.83 ) was only extracted (more than $45 \%$ ).

The recoveries using a $\mathrm{C}_{18}-\mathrm{CX}$ column were greater than those using a $\mathrm{C}_{18}$ column. Since $\mathrm{BBs}$ and $\mathrm{CCBs}$ can hold a positive charge when $\mathrm{pH}<\mathrm{p} K_{\mathrm{a}}$, as shown in Table 1 , cationexchangers including mixed-mode and strong cation exchange cartridges could be of interest. The $\mathrm{C}_{18}$-CX column exhibited a dual mode of action, consisting of both a cation-exchange and an apolar mechanism. Both modes were capable of retaining the aromatic and aliphatic amines. These two types of amines had low affinities to the $\mathrm{C}_{18}$ column due to column's dependence on $\log P$, but were retained on the CX column due to the cationexchange mechanism. Combining different interaction mechanisms (e.g., mixed-mode sorbent with similar $\pi-\pi$ interactions and ionic exchange capacity) with $\mathrm{C}_{18}-\mathrm{CX}$ can be useful for the extraction of a variety of compounds, but it can also lead to coextraction of matrix compounds that are not of interest, leading to more ion suppression in the HPLC-MS in the final analysis.

Matrix Effects. Co-eluting matrix components, which are not observed in the chromatogram, can have a detrimental effect on the analysis, since they can cause ion suppression or enhancement of the analyte. In this study, ion suppression was observed for nitrendipine and felodipine, as shown in Figure 2. The use of an organic solvent in the mobile phase was shown to reduce the ion suppression. Thus, when using methanol in the mobile phase, felodipine was suppressed, while nitrendipine was suppressed by using acetonitrile. After taking into consideration the fact that the therapeutic concentrations of nitrendipine is greater than that of felodipine, as shown in Table 1, acetonitrile was adopted as the organic solvent of the mobile phase.

Validation. Serum samples spiked with $2-500 \mathrm{ng} / \mathrm{mL}$ of the target drugs were prepared in triplicate at eight different concentrations and were analyzed using the procedure described above. Calibration curves were obtained by plotting the target drug/IS peak area ratio against the respective drug concentrations. A linear curve was observed for drug concentrations of up to

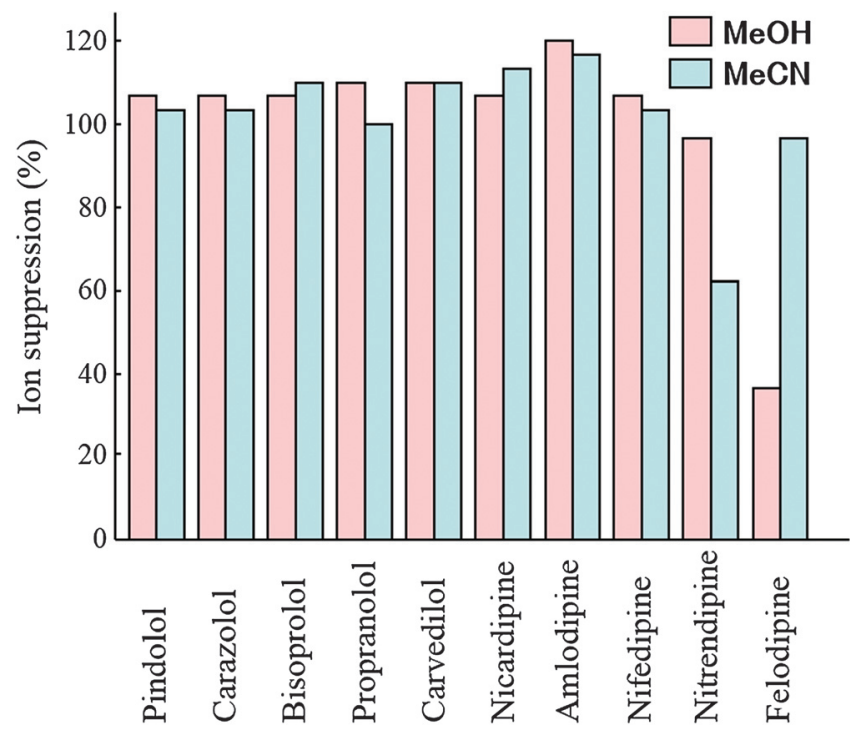

Figure 2. Effect of ion suppression on the mobile phase
$500 \mathrm{ng} / \mathrm{mL}$, as shown in Table 2. The correlation coefficients of the calibration curves were greater than 0.997 , as can be seen in Table 2. The lowest limit of quantification in the serum was $5 \mathrm{ng} / \mathrm{mL}$ for all the tested drugs. The signal-to-noise ratio $(S / N)$ was greater than 10 , and RSD was less than $\pm 15 \%$ (within $20 \%$ of the target). The detection limits in the serum were $2 \mathrm{ng} / \mathrm{mL}$ $(S / N=3)$ for all the targets. The recovery rates of the analytes in serum were $76-108 \%$, and the RSDs of the intra-day reproducibilities for serum samples containing 10, 200, and $400 \mathrm{ng} / \mathrm{mL}$ of drugs were $0.6-9.6 \%$ (Table 3 ). There was no possibility of sample contamination, since the samples and solvents flowed in the same direction, and the spin column was disposable. In conventional solid-phase extraction, the flow rate of the sample is checked carefully to ensure that the cartridge does not dry up because of the effects of recovery. Unlike cartridge extraction, in our procedure, the flow of the sample was easily controlled by the rotational speed of a centrifuge, and the sorbent is unlikely to dry up; thus, the accuracy and precision of extraction can be easily maintained. A typical chromatogram is shown in Figure 3. No endogenous substance overlapped with the target drugs.

Clinical Application. A 20-year-old woman was suspected of having ingested medications, as reported by her family members. After $2 \mathrm{~h}$, she visited the hospital and was admitted. The next day, her blood pressure decreased, and she developed dyspnea and was admitted to the intensive care unit (ICU).

Table 2. Range of linearity and correlation coefficients in serum

\begin{tabular}{|c|c|c|c|c|}
\hline & $\begin{array}{c}\text { LOD } \\
(\mathrm{ng} / \mathrm{mL})\end{array}$ & $\begin{array}{l}\text { Range of } \\
\text { linearity } \\
(\mathrm{ng} / \mathrm{mL})\end{array}$ & Linearity $^{\mathrm{a}}$ & $\begin{array}{l}\text { Correlation } \\
\text { coefficient }\end{array}$ \\
\hline \multicolumn{5}{|l|}{$\beta$-blocker } \\
\hline Pindolol & 2 & $5-500$ & $y=0.0017 x+0.0186$ & 0.997 \\
\hline Carazolol & 2 & $5-500$ & $y=0.0040 x+0.0145$ & 0.999 \\
\hline Bisoprolol & 2 & $5-500$ & $y=0.0036 x+0.0110$ & 0.999 \\
\hline Propranolol & 2 & $5-500$ & $y=0.0020 x+0.0055$ & 0.999 \\
\hline Carvedilol & 2 & $5-500$ & $y=0.0027 x+0.0105$ & 0.999 \\
\hline \multicolumn{5}{|l|}{ Ca-blocker } \\
\hline Nicardipine & 2 & $5-500$ & $y=0.0021 x+0.0040$ & 0.999 \\
\hline Amlodipine & 2 & $5-500$ & $y=0.0010 x+0.0065$ & 0.998 \\
\hline Nifedipine & 2 & $5-500$ & $y=0.0011 x+0.0009$ & 0.998 \\
\hline Nitrendipine & 2 & $5-500$ & $y=0.0022 x+0.0017$ & 0.999 \\
\hline Felodipine & 2 & $5-500$ & $y=0.0012 x-0.0016$ & 0.999 \\
\hline${ }^{a} x$ is the co & $\begin{array}{l}\text { tration } \\
\text { nit of }\end{array}$ & $\begin{array}{l}\text { target di } \\
\text { ection }\end{array}$ & $\mathrm{gs}(\mathrm{ng} / \mathrm{mL})$, and $y$ is the & eak area \\
\hline
\end{tabular}

Table 3. Intra-day coefficients of variation of the proposed method

\begin{tabular}{|c|c|c|c|c|c|}
\hline & \multicolumn{2}{|c|}{ Intra-day $(n=5)^{a}$} & & \multicolumn{2}{|c|}{ Intra-day $(n=5)^{a}$} \\
\hline & Mean \pm SD & CV $(\%)$ & & Mean \pm SD & CV $(\%)$ \\
\hline \multicolumn{3}{|c|}{$\beta$-blocker } & \multicolumn{3}{|c|}{ Ca-blocker } \\
\hline \multicolumn{3}{|c|}{ Pindolol } & \multicolumn{3}{|c|}{ Nicardipine } \\
\hline 10 & $9.8 \pm 0.6$ & 6.5 & 10 & $9.8 \pm 0.3$ & 3.3 \\
\hline 100 & $101.0 \pm 3.2$ & 3.1 & 100 & $103.4 \pm 2.7$ & 2.6 \\
\hline 400 & $384.3 \pm 31.3$ & 8.2 & 400 & $397.2 \pm 4.2$ & 1.1 \\
\hline \multicolumn{3}{|c|}{ Carazolol } & \multicolumn{3}{|c|}{ Amlodipine } \\
\hline 10 & $10.0 \pm 0.2$ & 1.5 & 10 & $10.3 \pm 0.4$ & 4.0 \\
\hline 100 & $99.4 \pm 2.8$ & 2.9 & 100 & $102.4 \pm 2.5$ & 2.4 \\
\hline 400 & $399.1 \pm 4.0$ & 1.0 & 400 & $399.2 \pm 4.8$ & 1.2 \\
\hline \multicolumn{3}{|c|}{ Bisoprolol } & \multicolumn{3}{|c|}{ Nifedipine } \\
\hline 10 & $9.8 \pm 0.3$ & 3.5 & 10 & $9.8 \pm 0.4$ & 3.7 \\
\hline 100 & $102.6 \pm 2.7$ & 2.6 & 100 & $96.1 \pm 3.1$ & 3.2 \\
\hline 400 & $394.2 \pm 5.5$ & 1.4 & 400 & $409.1 \pm 13.1$ & 3.2 \\
\hline \multicolumn{3}{|c|}{ Propranolol } & \multicolumn{3}{|c|}{ Nitrendipine } \\
\hline 10 & $0.38 \pm 0.02$ & 4.6 & 10 & $9.8 \pm 0.2$ & 1.7 \\
\hline 100 & $20.32 \pm 0.49$ & 2.4 & 100 & $99.7 \pm 2.5$ & 2.5 \\
\hline 400 & $40.05 \pm 0.93$ & 2.3 & 400 & $389.2 \pm 2.2$ & 0.6 \\
\hline \multicolumn{3}{|c|}{ Carvedilol } & \multicolumn{3}{|c|}{ Felodipine } \\
\hline 10 & $9.7 \pm 0.3$ & 3.2 & 10 & $10.1 \pm 1.0$ & 9.6 \\
\hline 100 & $100.8 \pm 1.7$ & 1.6 & 100 & $99.8 \pm 2.8$ & 2.8 \\
\hline 400 & $398.0 \pm 4.3$ & 1.1 & 400 & $402.1 \pm 4.1$ & 1.0 \\
\hline
\end{tabular}



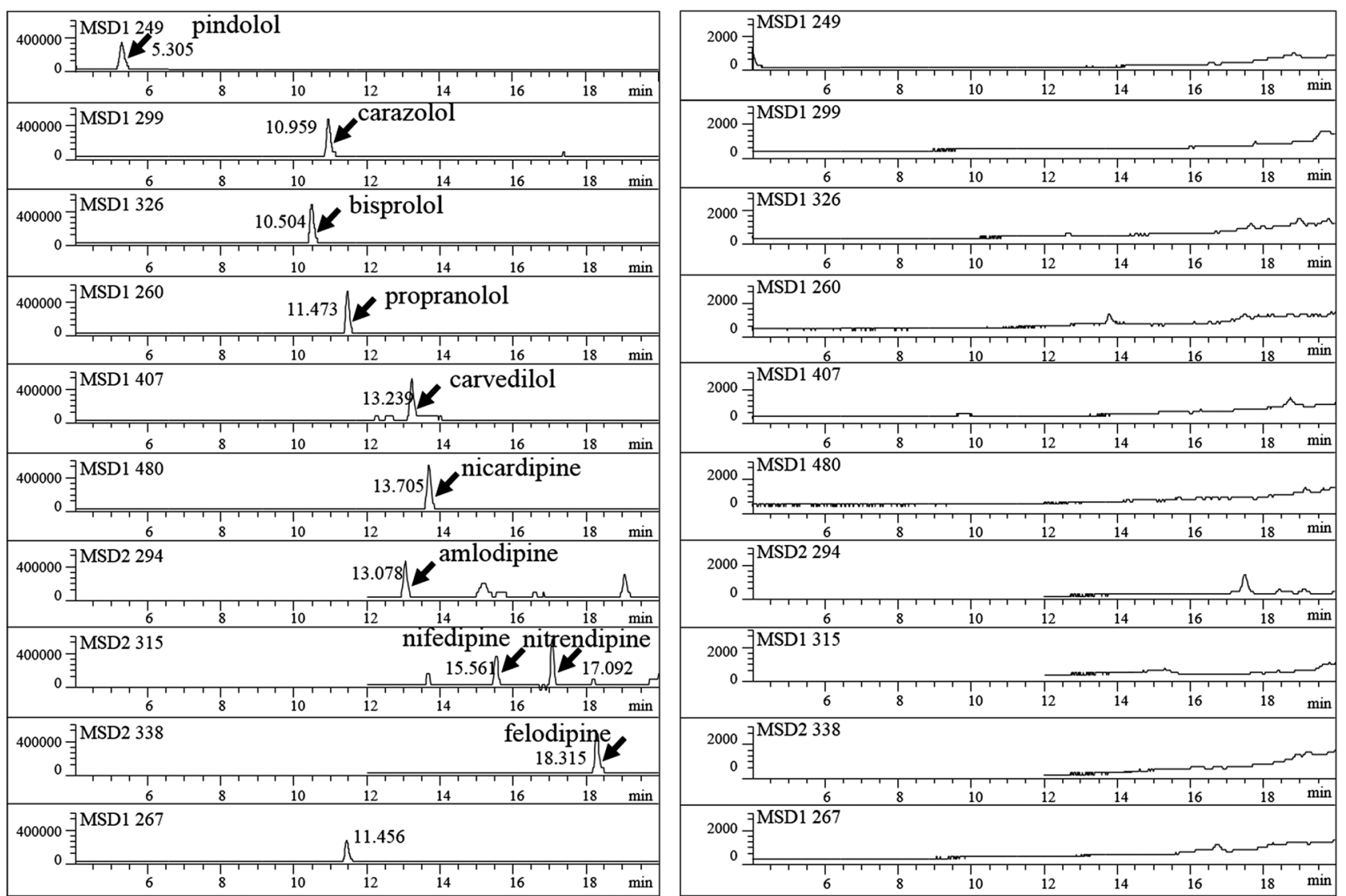

Figure 3. Representative chromatograms of $\beta$-blockers and calcium blockers obtained using HPLC-MS analysis for human serum. Left side: spiked serum with standards at the concentration of $250 \mathrm{ng} / \mathrm{mL}$. Right side: blank serum

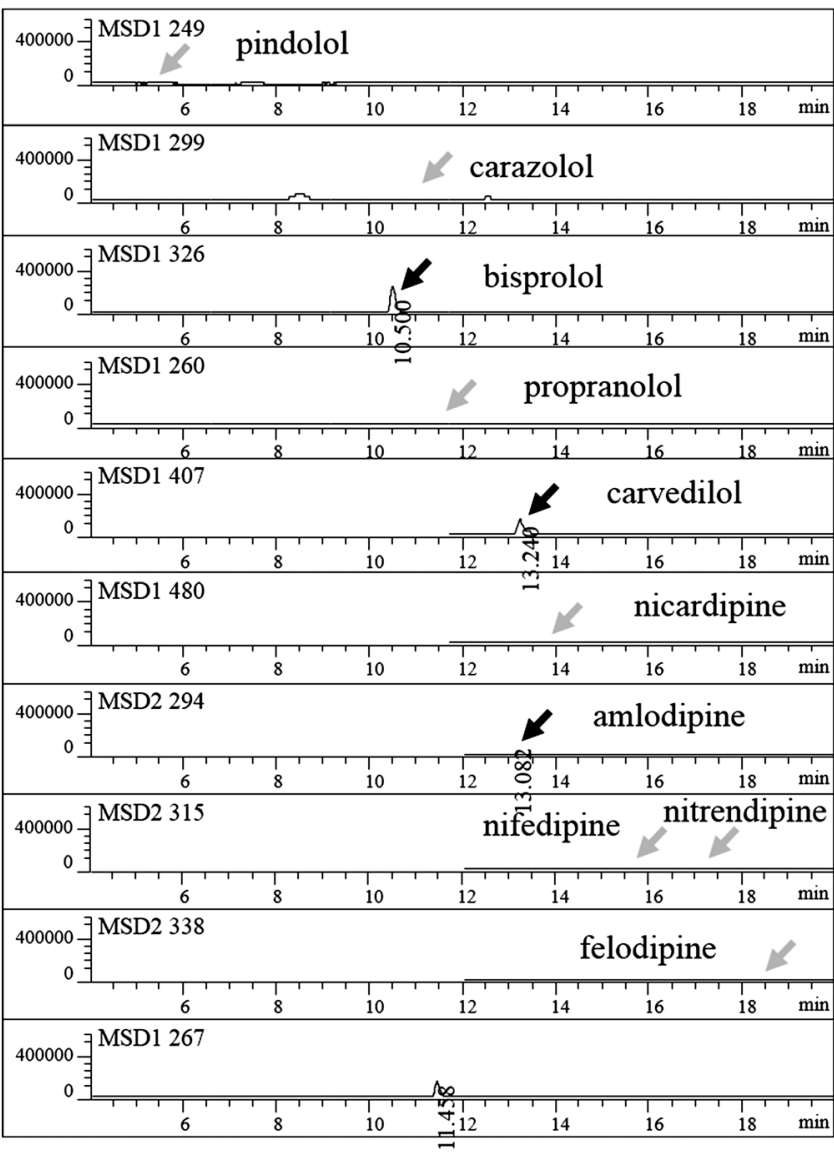

Figure 4. Representative chromatograms of $\beta$-blockers and calcium blockers obtained using HPLC-MS analysis for human serum in the case of toxicity
Serum samples collected from her were assayed using the proposed MonoSpin column extraction using the HPLC-MS method. Typical mass chromatograms of the serum sample on admission are shown in Figure 4. The concentrations of carvedilol, bisoprolol, and amlodipine were 530, 470, and $18 \mathrm{ng} / \mathrm{mL}$, respectively. After treatment, she was moved out of the ICU and discharged from the hospital, 75 days after being admitted.

\section{Conclusion}

This proposed extraction procedure using a MonoSpin ${ }^{\circledR}$ column is suitable for HPLC-MS analysis because it is easy to perform the extraction of analytes from human serum. Moreover, contamination is avoided by using a disposable column, and low-volume solvents are employed for elution of the analyte from the column. The most impressive aspect of this proposed method is the absence of the tedious evaporation step after elution of the analyte. The proposed procedure can be extended to the identification of other drugs in biological samples, and additional applications will be developed, including use of an extraction procedure for routine analysis.

\section{Funding Sources}

This work was supported in part by a Grant-in-Aid for Scientific Research (C) (No. 19590673) from the Japan Society for the Promotion of Science.

\section{Disclosures and Ethics}

Authors disclose no funding sources. Authors disclose no potential conflicts of interest. Serum was collected from a patient after obtaining informed consent, and experiments relating to 
clinical case were performed in accordance with the guidelines of the Ethical Committee of Hiroshima University.

Acknowledgements. The authors would like to thank S. Ohta, H. Oikawa, and S. Miyazaki of GL Sciences (Saitama, Japan) for technical assistance with the experiments.

\section{References}

1. World Health Organization Statistical Information System, Estimates for 2000-2015, CAUSE-SPECIFIC MORTALITY, http://www.who.int/healthinfo/ global_burden_disease/estimates/en/index1.html.

2. de Cătes, A. N.; Farr, M. R.; Wright, N.; Jarvis, M. C.; Rees, K.; Ebrahim, S.; Huffman, M. D. Cochrane Database Syst. Rev. 2014, 16, CD009868.

3. Wald, D. S.; Law, M.; Morris, J. K.; Bestwick, J. P.; Wald, N. J. Am. J. Med. 2009, 122, 290-300

4. Patel, Y. P.; Patil, S.; Bhoir, I. C.; Sundaresan, M. J Chromatogr. A 1998, 828, 283-286

5. Graudins, A.; Lee, H. M.; Druda, D. Br. J. Clin. Pharmacol. 2016, 81, 453-461.

6. Thakrar, R.; Shulman, R.; Bellingan, G.; Singer, M. BMJ Case Rep. 2014, pii: bcr2014204732.

7. Newton, C. R.; Delgado, J. H.; Gomez, H. F. Sem. Respir. Crit. Care Med. 2002, 23, 19-25.
8. Schulz, M.; Schmoldt, A. Pharmazie 2003, 58, 447-474.

9. Franke, U.; Munk, A.; Wiese, M. J. Pharm. Sci. 1999, 88, 89-95.

10. Zeng, L.; Li, Y.; Wu, X.; Zhang, J.; Xie, J.; Sun, C. J. Chromatogr. Sci. 2015, 53, 1611-1621.

11. Caron, G.; Steyaert, G.; Pagliara, A.; Reymond, F.; Crivori, P.; Gaillard, P.; Carrupt, P. A.; Avdeef, A.; Comer, J.; Box, K. J.; Girault, H. H.; Testa, B. Helv. Chim. Acta 1999, 82, 1211-1222.

12. Goryński, K.; Kiedrowicz, A.; Bojko, B. J. Pharm. Biomed. Anal. 2016, 127, 147-155.

13. Gu, H. W.; Wu, H. L.; Yin, X. L.; Li, Y.; Liu, Y. J.; Xia, H.; Zhang, S. R.; Jin, Y. F.; Sun, X. D.; Yu, R. Q.; Yang, P. Y.; Lu, H. J. Anal. Chim. Acta 2014 $848,10-24$.

14. Delamoye, M.; Duverneuil, C.; Paraire, F.; de Mazancourt, P.; Alvarez, J. C. Forensic Sci. Int. 2004, 141, 23-31.

15. Baranda, A. B.; Mueller, C. A.; Alonso, R. M.; Jiménez, R. M.; Weinmann, W. Ther. Drug Monit. 2005, 27, 44-52.

16. Wei, X.; Yang, G.; Qi, L.; Chen, Y. Talanta 2009, 77, 1197-1202.

17. Rezk, M. R.; Badr, K. A. J. Pharm. Biomed. Anal. 2014, 98, 1-8.

18. Kristoffersen, L.; Øiestad, E. L.; Opdal, M. S.; Krogh, M.; Lundanes, E.; Christophersen, A. S. J. Chromatogr. B: Anal. Technol. Biomed. Life Sci. 2007, 850, 147-160.

19. Dias, E.; Hachey, B.; McNaughton, C.; Nian, H.; Yu, C.; Straka, B.; Brown, N. J.; Caprioli, R. M. J. Chromatogr. B: Anal. Technol. Biomed. Life Sci. 2013, 937, 44-53.

20. Namera, A.; Nakamoto, A.; Nishida, M.; Saito, T.; Kishiyama, I.; Miyazaki, S.; Yahata, M.; Yashiki, M.; Nagao, M. J. Chromatogr. A 2008, 1208, 71-75.

21. Nakamura, M.; Nakamura, M.; Yamada, S. Analyst 1996, 121, 469-475. 